\title{
Kentsel Peyzaj Değişiminin Zamansal ve Mekansal Analizi: Burdur Kenti Örneği
}

\author{
Yasin AŞIK ${ }^{*}$, Gülşah KAÇMAZ ${ }^{1}$ \\ ${ }^{1}$ Burdur Mehmet Akif Ersoy Üniversitesi, Mühendislik Mimarlık Fakültesi, Peyzaj Mimarlı̆g Bölümü, 15030, \\ BURDUR
}

\section{Öz}

Bu araştırmada, 2012 ve 2018 arazi kullanım/arazi örtüsü (AKAÖ) haritaları kullanılarak Burdur İli Merkez İlçesi'nde peyzaj değişiklikleri incelenmiştir. Veri analizinde ArcMap 10.8 ve FRAGSTATS ${ }^{\text {TM }} 4.2$ yazılımlarından faydalanılmıştır. AKAÖ üzerindeki değişiklikler Sınıf Alanı (CA), Parça Sayısı (NP), Parça Yoğunluğu (PD), Peyzajın Oranı (PLAND) ve Ortalama Parça Büyüklüğü (AREA_MN) metrikleri kullanılarak belirlenmiştir. 2012 ve 2018 yılları arasında maden/inşaat/kullanılmayan araziler en büyük artışı (\%122,34) göstermişken, en büyük azalış $(\% 19,68)$ sulak alanlarda meydana gelmiştir. AKAÖ sınıfları arasında en büyük dönüşüm (7.016,07 ha) tarımsal alanlar ile doğal/yarı doğal alanlar arasında olmuştur. Endüstriyel/ticari alanlarda ve sulak alanlarda parçalanma artmış, tarımsal alanlarda ve doğal/yarı doğal alanlarda ise parçalanma azalmıştır. Sonuç olarak, 6 yıl gibi kısa bir sürede meydana gelen peyzaj değişimleri önemli soru işaretlerini gündeme getirmektedir. Bu değişiklikler hiç şüphesiz ekosistem hizmetlerini ve ekolojik süreçleri olumsuz etkileyecektir. Ekosistem hizmetleri ve ekolojik süreçlerin aksamaması için gerekli önlemler alınmalıdır. Burdur kenti için geniş kapsamlı bir kentsel yeşil altyapı stratejisi ve planının hazırlanması bu yolda önemli bir adım olacaktır.

Anahtar Kelimeler: Peyzaj deseni, peyzaj değişimi/dönüşümü, peyzaj ekolojisi, peyzaj metrikleri, peyzaj parçalanması.

\section{Temporal and Spatial Analysis of Urban Landscape Change: The Case of Burdur, Turkey}

\begin{abstract}
In this study, were examined landscape changes in the Central District of Burdur Province using 2012 and 2018 land use/land cover (LULC) maps. ArcMap 10.8 and FRAGSTATS ${ }^{\text {TM }} 4.2$ software were used for data analysis. Changes on LULC were determined using Class Area (CA), Number of Patch (NP), Patch Density (PD), Proportion of Landscape (PLAND) and Mean Patch Size (AREA_MN) metrics. Between 2012 and 2018, mining/construction/vacant land showed the greatest increase $(122,34 \%)$. The biggest decrease $(19,68 \%)$ occurred in wetlands. The biggest transformation (7.016,07 ha) among LULC classes has been between agricultural areas and natural/semi-natural areas. Fragmentation has increased in industrial/commercial areas and wetlands, whereas fragmentation has decreased in agricultural areas and natural/semi-natural areas. As a result, landscape changes in a short period of 6 years raise important question marks. These changes will undoubtedly affect ecosystem services and ecological processes negatively. Thus, necessary measures should be taken to prevent disruption of ecosystem services and ecological processes. The preparation of a comprehensive urban green infrastructure strategy and plan for the city of Burdur will be an important step in this direction.
\end{abstract}

Keywords: Landscape pattern, landscape change/transformation, landscape ecology, landscape metrics, landscape fragmentation.

\footnotetext{
*Sorumlu Yazar (Corresponding Author):

Yasin AŞIK (Arş. Gör.); Burdur Mehmet Akif Ersoy Üniversitesi, Mühendislik

Mimarlık Fakültesi, Peyzaj Mimarlığı Bölümü, 15030, Burdur-Türkiye. Tel: +90 (248)

213 2782, Fax: +90 (248) 213 2704, E-mail: yasik@mehmetakif.edu.tr 


\section{Giriş}

Başta kentleşme olmak üzere insan aktiviteleri peyzajın yapısı ve işlevleri üzerinde zaman içinde çok önemli değişimler yaratmış ve yaratmaktadır (Money vd., 2013; Lawler vd., 2014; Khan vd., 2015; Paudel vd., 2015; Roth vd., 2016). Doğal ve tarımsal peyzajlar zaman içinde değişim geçirmekte, parçalanmakta ve giderek yok olmaktadır (Hepcan vd., 2012; Hepcan, 2013). Özellikle sanayileşme ile birlikte, değişime neden olan insan faaliyetleri yoğunluk kazanmış (Zhang vd., 2010), peyzajın yapısı ve doğal peyzaj dinamiklerindeki değişimlerin nedeni olarak insan faaliyetleri önemli bir etken haline gelmiştir (Petropoulos vd., 2015; Singh vd., 2016). Bu değişiklikler, doğal ekosistemlerin işleyişini bozarak başta iklim değişikliği olmak üzere (Rocchini vd., 2006; Singh vd., 2016), habitat (Singh vd., 2016) ve biyolojik çeşitlilik kaybı (Moser vd., 2002; Rocchini vd., 2006; Butt vd., 2015), seller, su miktarında ve kalitesinde azalma (Singh vd., 2015; Kumar vd., 2017; Kumar vd., 2018), kentsel 1sı adası gibi pek çok soruna neden oluştur.

Peyzajın yapısı ve işlevleri üzerinde meydana gelen değişimler aynı zamanda, ekosistemlerden sağlanan hizmetleri de olumsuz etkilemektedir. Ekosistemler, özellikle doğal ekosistemler (Costanza vd., 1997) insanlara sağladığı çeşitli kaynaklar ve servisler açısından çok önemlidir (Bolliger ve Kienast, 2010; Mitchell vd., 2015; Renó vd., 2016). Hiç şüphesiz peyzajda yaşanan değişimler ekosistem hizmetlerinin sürdürülmesinde kilit bir rol oynamaktadır (Bateman vd., 2013). Bu değişikler ekosistem hizmetlerini doğrudan etkilerken (Haberl vd., 2001; Lorencová vd., 2013; Hao vd., 2017), ekolojik süreçleri de aynı şekilde etkileyebilmektedir (Hao vd., 2017; Tanner ve Fuhlendorf, 2018).

Başta kentsel peyzajlar olmak üzere peyzajda yaşanan bu değişimlerin saptanması, analiz edilip yorumlanması, hızlı kentleşme ile doğal ve tarım alanların dönüşümü gibi konulara yönelik sürdürülebilir planlama ve yönetim kararları geliştirilmesinde çok önemlidir (Syrbe ve Walz, 2012; Zhang vd., 2016; Drummond ve Loveland, 2010; Agaton vd., 2016). Peyzaj metrikleri, peyzajda yaşanan yapısal ve işlevsel değişimleri niceliksel olarak ölçmek ve yorumlamak için kullanılan yaygın bir analiz yöntemidir (McGarigal ve Marks, 1995; McGarigal ve Cushman, 2002).

Bu araştırmada; Burdur Merkez İlçesinde 2012-2018 yılları arasında peyzajda meydana gelen değişimler peyzaj metrikleri vasıtasıyla (Sınıf Alanı-CA, Parça Sayısı-NP, Parça Yoğunluğu-PD, Peyzajın Oranı-PLAND ve Ortalama Parça Büyüklüğü-AREA_MN) analiz edilerek mevcut ve gelecekteki mekansal gelişmelere 1 şık tutmak amacıyla yorumlanmıştır.

$\mathrm{Bu}$ araştırmayı önemli kılan iki temel unsur mevcuttur. Birincisi, Burdur kent peyzajının Burdur Gölü Havzasının da yer alması ve özellikle sulak alanlar ve doğal/yarı doğal alanlar açısından çok zengin bir doğal peyzaja sahip olmasıdır. Ancak gölde su seviyesinin azalması, sürdürülebilir olmayan sulak alan yönetimi, madencilik faaliyetlerin artışı ve çevreye duyarlı ve sürdürülebilir olmayan tarımsal faaliyetler gibi sebepler Burdur peyzajı üzerinde ciddi sorunlara ve değişimlere neden olmaktadır (Ataol, 2010; Yigitbaşığlu ve Uğur, 2010; Kaya vd., 2015). Diğer neden ise Burdur kent peyzajında geçmişten günümüze meydana gelen değişimlerin niceliksel olarak ve sistematik biçimde analiz edilip yorumlandığı çalışmaların yeterli sayıda olmamasıdır. Burdur kentinde bu bağlamda önemli bir eksiklik mevcuttur. Burdur kentinde alınacak fiziksel planlama kararlarına yön vermek açısından bu tür analiz ve yorumlamalara büyük ihtiyaç vardır.

\section{Materyal ve Metot}

\subsection{Materyal}

Araştırmanın temel materyalini araştırma alanı oluşturmaktadır. Araştırma alanını Burdur İlinin Merkez İlçesi

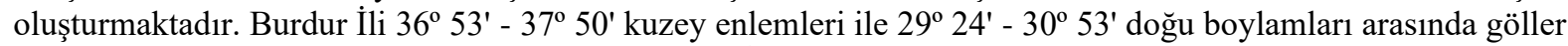
yöresi adı verilen bölgede yer almaktadır (Şekil 1). İlde iklim çoğunlukla yazları kurak ve sıcak, kışları soğuk ve yağışlı geçmektedir. Burdur doğuda Isparta, batıda Denizli, kuzeyde Afyonkarahisar ve güneyde Antalya ili ile çevrelenmektedir. Yüzölçümü 1.567 km² olup, TÜİK (2021)'e göre nüfusu 111.984'dur. 


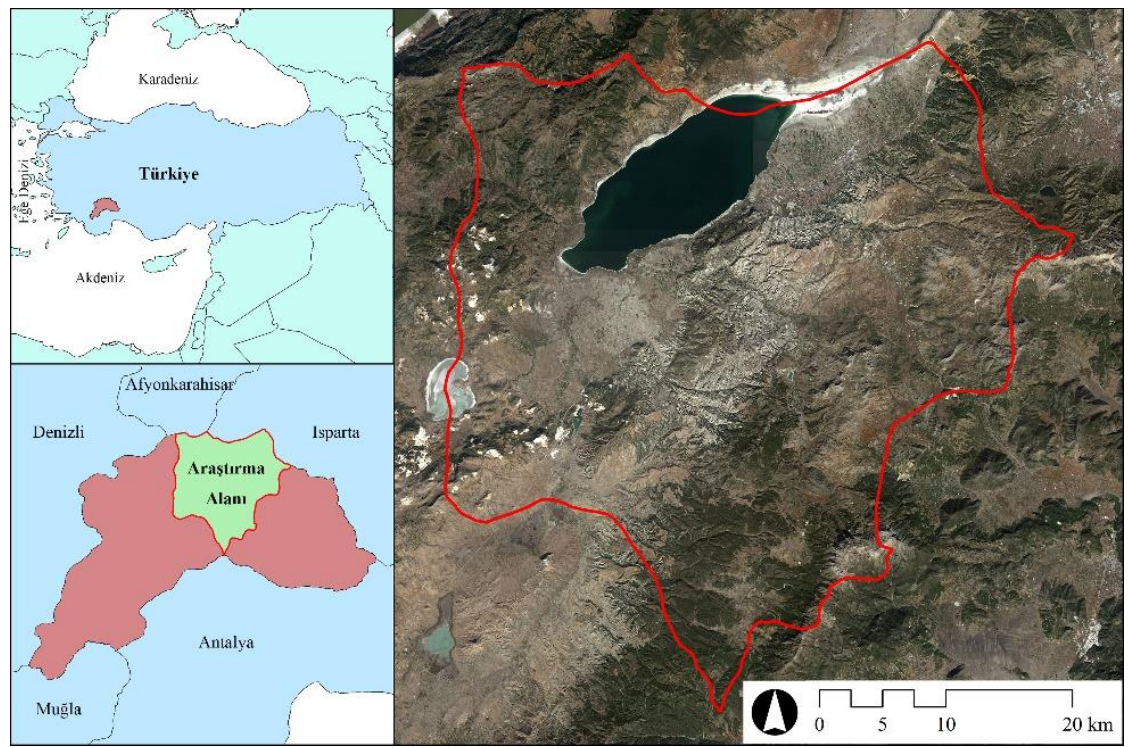

Şekil 1. Araştırma alanı.

Araştırmada kullanılan diğer materyal ise 2012 ve 2018 yıllarına ait Burdur Merkez İlçesi alan kullanım/arazi örtüsü (AKAÖ) haritalarıdır (EEA, 2020a). AKAÖ haritalarında 23 farklı sınıf tanımlamaktadır. Bunlardan 14'ü yapay yüzeyler, 4'ü tarımsal alanlar, 3'ü doğal-yarı doğal alanlar 1'er adeti su yüzeyleri ve sulak alanlarıdır. Yapay yüzey sınıflarının 6'sı kentsel doku düzeylerini $(11100,11210,11220,11230,11240$, 11300), 2'si ulaşım altyapısını (12220, 12230) ve geri kalan 6'sı diğer kullanımları (12100, 13100, 13300, 13400, 14100, 14200) belirtmektedir (Tablo 1). Veriler vektör formattadır. Her poligon bir AKAÖ sinıfını temsil etmektedir. Minimum haritalama birimi kentsel alanlarda 0.25 ha, kırsal alanlarda ise 1 ha'dir. Genel sınıflandırma doğrulu kentsel alanlarda \%85 ve üzerinde, kırsal alanlarda ise \%80 ve üzerindedir (EEA, 2020b).

Tablo 1. AKAÖ sinifları.

\begin{tabular}{ll}
\hline Kod & Sınıflar \\
\hline $\mathbf{1 1 1 0 0}$ & Sürekli kentsel doku (Geçirimsizlik Düzeyi: >\%80) \\
$\mathbf{1 1 2 1 0}$ & Süreksiz yoğun kentsel doku (Geçirimsizlik Düzeyi: \%50-\%80) \\
$\mathbf{1 1 2 2 0}$ & Süreksiz orta yoğunluklu kentsel doku (Geçirimsizlik Düzeyi: \%30-\%50) \\
$\mathbf{1 1 2 3 0}$ & Süreksiz düşük yoğunluklu kentsel doku (Geçirimsizlik Düzeyi: \%10-\%30) \\
$\mathbf{1 1 2 4 0}$ & Süreksiz çok düşük yoğunluklu kentsel doku (Geçirimsizlik Düzeyi: <\%10) \\
$\mathbf{1 1 3 0 0}$ & İzole yapılar \\
$\mathbf{1 2 1 0 0}$ & Endüstriyel, ticari, kamu, askeri ve özel birimler \\
$\mathbf{1 2 2 2 0}$ & Diğer yollar ve ilgili arazi \\
$\mathbf{1 2 2 3 0}$ & Demiryolları ve ilgili arazi \\
$\mathbf{1 3 1 0 0}$ & Maden çıarımı ve döküm alanları \\
$\mathbf{1 3 3 0 0}$ & İnşaat alanları \\
$\mathbf{1 3 4 0 0}$ & Mevcut kullanımı olmayan arazi \\
$\mathbf{1 4 1 0 0}$ & Kentsel yeşil alanlar \\
$\mathbf{1 4 2 0 0}$ & Spor ve eğlence tesisleri \\
$\mathbf{2 1 0 0 0}$ & Ekilebilir arazi (Yıllık ürünler) \\
$\mathbf{2 2 0 0 0}$ & Sürekli tarım alanları (Üzüm bağları, meyve ağaçları, zeytinlikler) \\
$\mathbf{2 3 0 0 0}$ & Meralar \\
$\mathbf{2 4 0 0 0}$ & Karmaşık ve karışık yetiştirme desenler \\
$\mathbf{3 1 0 0 0}$ & Ormanlar \\
$\mathbf{3 2 0 0 0}$ & Otsu bitki örtüsü birlikleri (Doğal otlaklar, kırlar ...) \\
$\mathbf{3 3 0 0 0}$ & Bitki örtüsü az olan veya hiç olmayan açık alanlar (Plajlar, kum tepeleri, çıplak kayalar, ...) \\
$\mathbf{4 0 0 0 0}$ & Sulak alanlar (İç sulak alan, kıyısal sulak alan) \\
$\mathbf{5 0 0 0 0}$ & Su yüzeyleri (Göl, kanal, nehir, ...) \\
\hline
\end{tabular}




\subsection{Metot}

Peyzajda meydana gelen değişim, dönüşüm ve parçalanmalar ile ilgili ayrıntılı bir analiz için AKAÖ yeniden sınıflandırılarak 11 sınıf altında toplanmıştır (Tablo 2). 11 sınıftan üçü kentsel doku alanlarını (S1, S2, S3) temsil etmektedir.

Burdur merkez ilçesinde AKAÖ sınıflarında meydana gelen değişim oranını ve hangi sınıflarda parçalanma olduğunu belirlemek amacıyla; Sınıf Alanı (CA), Parça Sayısı (NP), Parça Yoğunluğu (PD), Peyzajın Oranı (PLAND), ve Ortalama Parça Büyüklüğü (AREA_MN) olmak üzere 5 sınıf metriği kullanılmıştır (McGarigal ve Marks, 1995). Metriklerin hesaplanmasında FRAGSTATS ${ }^{\mathrm{TM}}$ yazılımından faydalanılmıştır (McGarigal vd., 2012). FRAGSTATS ${ }^{\mathrm{TM}}$ yazılımı yalnızca raster veri kabul ettiği için yeniden sınıflandırma işleminden sonra elde edilen vektör haritası pixel başına $3 \times 3 \mathrm{~m}$ çözünürlükte raster veriye dönüştürülmüştür. AKAÖ sınıfları arasında meydana gelen dönüşümlerin belirlenmesinde ise ArcMap 10.8 yazılımı kullanılmıştır (ESRI, 2020).

Tablo 2. Metrik analizi için AKAÖ sınıflandırması.

\begin{tabular}{lll}
\hline Sınıflar & Sınıf Tanımı & AKAÖ Kodu \\
\hline S1 & Sürekli kentsel doku & 11100 \\
S2 & Süreksiz yoğun kentsel doku & 11210 \\
S3 & Süreksiz kentsel doku & $11220,11230,11240,11300$ \\
S4 & Endüstriyel/ticari alanlar & 12100 \\
S5 & Ulaşım altyapısı & 12220,12230 \\
S6 & Maden / İnşaat / Kullanılmayan arazi & $13100,13300,13400$ \\
S7 & Kentsel yeşil alanlar / Spor tesisleri & 14100,14200 \\
S8 & Tarımsal alanlar & $21000,22000,23000,24000$ \\
S9 & Doğal/yarı doğal alanlar & $31000,32000,33000$ \\
S10 & Sulak alanlar & 40000 \\
S11 & Su yüzeyleri & 50000 \\
\hline
\end{tabular}

\section{Bulgular ve Tartışma}

2012 y1lında Burdur merkez ilçesinin \%56,86'sını doğal/yarı doğal alanlar (S9) (Ormanlar, otsu bitki örtüsü birlikleri ve bitki örtüsü az olan veya hiç olmayan açık alanlar) oluşturmaktadır. Bunu sırasıyla \%30,32 ve $\% 8,90$ ile tarımsal alanlar (S8) ve su yüzeyleri (S11) takip etmektedir. Kentsel doku incelendiğinde ise \%0,91 ile süreksiz kentsel doku (S3) en yüksek alanı kaplamakta, onu \%0,37 ile süreksiz yoğun kentsel doku (S2) izlemektedir (Tablo 3; Şekil 2).

Süreksiz kentsel doku ve süreksiz yoğun kentsel dokunun fazla olması Burdur Merkez İlçesindeki yerleşimin, bahçeli müstakil evlerden veya aralarında açık yeşil alanların yer aldığı dağınık apartman bloklarından meydana geldiğini göstermektedir. Ayrıca Burdur merkez ilçenin yarıdan fazlasının doğal/yarı doğal alanlarla kaplı olduğu ve yapılı alanın-ki aynı zamanda geçirimsiz yüzeyleri de temsil etmektedir- oldukça küçük bir yer işgal ettiğini göstermektedir. Hatta günümüzde kent tarımının ve kentlinin ihtiyacı olan sağlıkl gıda üretiminin önemi düşünüldüğünde, kentte tarımsal arazi kullanım biçiminin \%30 civarında olması çok önemli bir potansiyeldir.

2018 yılında doğal/yarı doğal alanlar \%1,13 bir artış göstermiş ve Burdur merkez ilçesinin \%57,51'ini kaplamıştır. En büyük değişim \%122,34 artı̧̧ ile maden/inşaat/kullanılmayan araziler (S6) de meydana gelmiştir. Maden/inşaat/kullanılmayan arazilerin \%0,47 olan kaplama oranı \%1,05'e çıkmıştır. Maden/inşaat/kullanılmayan arazileri sırasıyla $\% 52,85$ ve $\% 47$ artış oranıyla endüstriyel/ticari alanlar (S4) ile kentsel yeşil alanlar/spor tesisleri (S7) izlemektedir. Kentsel dokuda en büyük artış süreksiz kentsel dokuda meydana gelmiştir. Süreksiz kentsel doku \%11,90 oranında artmış, alan büyüklügü̈ 1.591,18 ha ve kaplama oranı \%1,01 olmuştur. Bu durum merkez ilçede hızlı bir kentleşmeyle birlikte geçirimsiz yüzeylerinde hızlı bir biçimde artığını göstermektedir. 2018 yılında en büyük azalış sulak alanlarda meydana gelmiştir. 2012 yılında mevcut alanın \%1,12'sini kaplayan sulak alanlar, 2018 y1lında \%19,68 oranında azalarak mevcut alanın $\% 0,90$ 'ını kaplamaktadır. Sulak alanları sırasıyla $\% 4,16$ ve $\% 1,07$ azalış oranıyla tarımsal alanlar ve su yüzeyleri takip etmektedir. (Tablo 3; Şekil 2).

Mevcut pek çok araştırma (Alphan, 2003; Hepcan vd., 2013; Kara vd., 2013; Dengiz ve Turan, 2014; Turgut vd., 2021) kentleşme süreci içinde tarım alanlarının önemli ölçüde kaybından söz etmektedir. Karaali vd. (2020) 
1990-2019 yılları arasında İzmir kentinde yapay yüzeylerin \%12,4 oranında artışından söz ederken tarım alanları, su yüzeyleri ve orman alanlarının sırasıyla \%1,21, \%0,25 ve \%2,9 oranında azaldığını belirtmektedir. Buna karşın Bayar ve Karabacak (2017), Ankara'da yaptıkları çalışmada 2000-2012 yılları arasında tarım alanlarında yıllık \%0,16 oranında azalma olduğunu, sırasıyla yerleşim alanları ve sulak alanların yıllık \%1,49 ve $\% 0,33$ artış gösterdiğini belirtmektedir. Sulak alanlardaki artışın sebebini ise Ankara kentinde yıllar içinde yapılan barajlar olarak göstermektedirler. Aynı şekilde Uzun vd. (2015) Yeşilırmak Havzası'nda gerçekleştirdikleri araştırmada su yüzeylerinin arttı̆̆ını ve sulanan tarımsal alanların azalarak, sulanmayan tarımsal alanlara dönüştüğünü belirtmişlerdir. Bu durum sürdürülebilir su yönetimi açısından oldukça olumlu bir sonuçtur. Aksine Burdur Merkez İlçesinde kısa bir süre içerisinde ciddi bir sulak alan azalması meydana gelmiştir. Kısa bir süre içindeki sulak alanlardaki bu azalma, Burdur'un en önemli doğal peyzaj değerlerinden olan sulak alan ekosistemi için son derece olumsuz bir gelişmeye işaret etmektedir. Sulak alanlardaki azalma aynı zamanda biyo-çeşitlilik kaybı anlamına da gelmektedir. Benzer şekilde Hepcan vd. (2013), İzmir kentinde 1963 ve 2005 yılları arasında sadece Gediz deltasında \%40’dan fazla bir sulak alan kaybının olduğunu belirtmiştir. Kara (2019)'da İzmir İnciraltı'nda yaptığı çalışmada 1996 ve 2018 yılları arasında \%167,41 oranında bir azalmanın olduğunu gündeme getirmiştir. Zadbagher vd. (2018) ise Seyhan Havzasında yaptıkları çalışmada 2006 ve 2016 yılları arasında yaklaşık 1,5 km² bir sulak alan kaybının yaşandığını belirtmektedir. Ayrıca tarımsal alanlardaki azalışın da dikkate alınması gereklidir. Mevcut araştırmalarla paralellik gösteren tarımsal alanlardaki azalmalar, Türkiye'de tarımsal alanların yeterince korunamadığını göstermektedir. Maden/inşaat/kullanılmayan arazilerde de artış mevcut araştırmalarla (Alkan vd., 2013; Kara vd., 2013; Gül vd., 2019) paralellik göstermektedir. Artışın temel nedeni Burdur ilinin sahip olduğu zengin mermer madeni rezervleridir. Maden/inşaat/kullanılmayan arazilerde meydana gelen artış doğal/yarı doğal alanları tehdit etmekte, Burdur ekosistemi üzerinde geri dönüşü zor zararlar vermektedir. Gül vd. (2019) artan madencilik faaliyetlerinin flora ve faunanın yanı sıra bölgedeki antik şehirlere de zarar verdiğini belirtmektedir.

Tablo 3. Burdur Merkez İlçesi AKAÖ sınıfları ve 2012-2018 arası değişimi.

\begin{tabular}{cccccc}
\hline AKAÖ & \multicolumn{2}{c}{$\mathbf{2 0 1 2}$} & \multicolumn{2}{c}{$\mathbf{2 0 1 8}$} & \multirow{2}{*}{$\begin{array}{c}\text { Değişim } \\
\text { (\%) }\end{array}$} \\
\cline { 2 - 5 } Sinıfları* & CA (ha) & PLAND (\%) & CA (ha) & PLAND (\%) & 2,90 \\
S1 & 86,64 & 0,06 & 89,15 & 0,06 & 2,18 \\
S2 & $588 ., 2$ & 0,37 & 601,06 & 0,38 & 11,90 \\
S3 & $1.422,02$ & 0,91 & $1.591,18$ & 1,01 & 52,85 \\
S4 & 591,27 & 0,38 & 903,74 & 0,58 & 3,49 \\
S5 & 889,84 & 0,57 & 920,86 & 0,59 & 122,34 \\
S6 & 738,42 & 0,47 & $1.641,82$ & 1,05 & 47,00 \\
S7 & 64,91 & 0,04 & 95,42 & 0,06 & $-4,16$ \\
S8 & $47.523,75$ & 30,32 & $45.545,50$ & 29,06 & 1,13 \\
S9 & $89.110,77$ & 56,86 & $90.120,75$ & 57,51 & $-19,68$ \\
S10 & $1.749,28$ & 1,12 & $1.404,96$ & 0,90 & $-1,07$ \\
S11 & $13.947,70$ & 8,90 & $13.798,38$ & 8,80 & - \\
\hline Toplam & $\mathbf{1 5 6 . 7 1 2 , 8 2}$ & $\mathbf{1 0 0}$ & $\mathbf{1 5 6 . 7 1 2 , 8 2}$ & $\mathbf{1 0 0}$ & \\
\hline
\end{tabular}

*S1; Sürekli kentsel doku, S2; Süreksiz yoğun kentsel doku, S3; Süreksiz kentsel doku, S4; Endüstriyel/ticari alanlar, S5; Ulaşım altyapıs1, S6; Maden /inşaat/kullanılmayan arazi, S7; Kentsel yeşil alanlar/spor tesisleri, S8; Tarımsal alanlar, S9;Doğal/yarı doğal alanlar, S10; Sulak alanlar, S11; Su yüzeyleri 


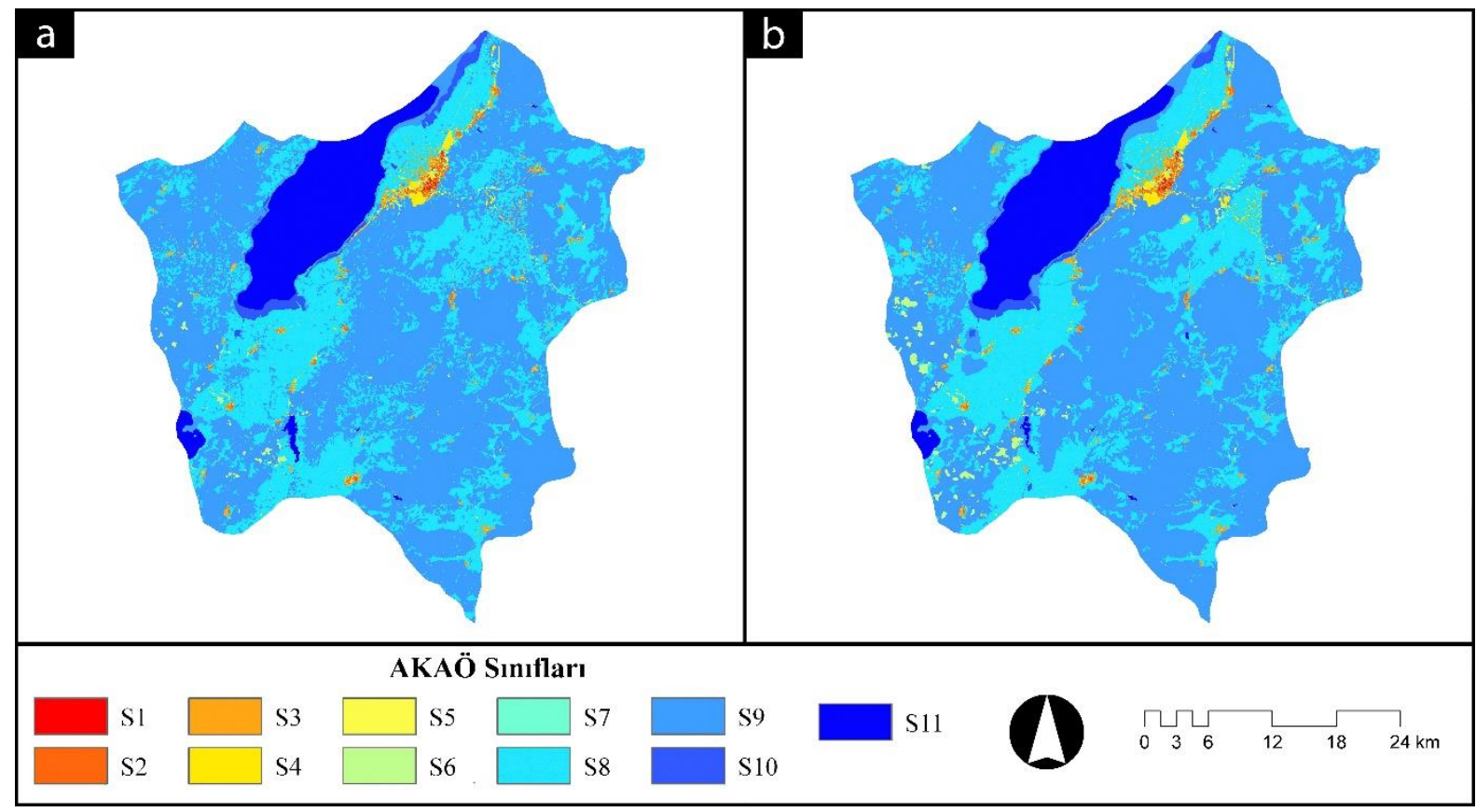

Şekil 2. Burdur Merkez İlçesi (a) 2012 ve (b) 2018 AKAÖ sınıfları (S1; Sürekli kentsel doku, S2; Süreksiz yoğun kentsel doku, S3; Süreksiz kentsel doku, S4; Endüstriyel/ticari alanlar, S5; Ulaşım altyapısı, S6; Maden /inşaat/kullanılmayan arazi, S7; Kentsel yeşil alanlar/spor tesisleri, S8; Tarımsal alanlar, S9;Doğal/yarı doğal alanlar, S10; Sulak alanlar, S11; Su yüzeyleri).

2012-2018 yılları arasında AKAÖ sınıfları arasında meydana gelen değişim ve dönüşümlerin daha net ortaya konulması için Tablo 4 hazırlanmıştır. 2018 yılında 2012 yılına göre tarımsal alanlar 141,96 ha, doğal/yarı doğal alanlar 126,82 ha azalarak endüstriyel/ticari alan olarak kullanılmaya başlanmıştır. 2012 yılında doğal/yarı doğal alan olan 824,74 ha ve tarımsal alan olarak kullanılan 172,10 ha alan da maden/inşaat/kullanılmayan arazilere dönüşmüştür. Tarımsal alan olan 20,32 ha alan kentsel yeşil alanlar/spor tesislerine dönüştürülmüştür. En büyük değişim tarımsal alanlar ile doğal/yarı doğal alanlar arasında meydana gelmiştir. 2012-2018 yılları arasında 7.016,07 ha tarımsal alan doğal/yarı doğal alanlara dönüşmüştür. Buna karşılık olarak ise 5.106,68 ha doğal/yarı doğal alan ise tarımsal alan olarak kullanılmaya başlanmıştır. En dikkat çekici bulgular arasında 2012 yılında sulak alan olan 397,15 ha alanın tarımsal alan olarak kullanılmaya başlaması olmuştur. 2018 yılında su yüzeylerinden kaybedilen 111,83 ha, 31,30 ha ve 27,89 ha alan sırasıyla doğal/yarı doğal alan, sulak alan ve tarımsal alan olarak sınıflandırılmıştır.

Burada dikkat çekici bir nokta; Burdur merkez ilçede kentsel dokunun ve dolayısıyla geçirimsiz yüzeylerin diğer alan kullanım biçimlerinin aleyhine olacak bir biçimde artmasıdır. Ancak, PLAND skorları bağlamında bu artış, örneğin 2005 yılında \%26 oranında yer işgal eden İzmir kentiyle karşılaştırıldığında (Hepcan, 2013), daha küçük bir oranda gerçekleşmiştir. Ayrıca mevcut çalışmalara (Oğuz ve Zengin, 2011; Bayar ve Karabacak, 2017; Turgut vd., 2021) paralel olarak kentsel dokudaki artışın büyük bir kısmı tarımsal alanlardan elde edilmiştir. Alphan (2003)'de Adana ilinde yaptığı araştırmada 1984 ve 2000 yılları arasında kentsel dokuya dönüştürülen tarımsal alanların neredeyse tamamının I. Sınıf ve II. Sınıf topraklar olduğunu belirtmiştir. Gıda üretimi açısından önemli olan tarımsal alanların farklı kullanımlara dönüştürülmesi ileride gıda üretiminde azalmalara sebep olabilecektir. Diğer kayda değer durum ise sulak alanların kurutularak tarımsal kullanıma açılmasıdır. Kara (2019) İzmir İncirlatı'nda yaptığı çalışmada sulak alanların yaklaşık \%30 oranında şantiyelere dönüştürüldüğünü belirtmiştir. Burdur kentinde ise sulak alanlarda meydana gelen azalışın temel sebebi olarak sulak alanların tarımsal alanlara dönüştürülmesi gelmektedir. Ayrıca tarım alanları ve doğal/yarı doğal alanlar arasındaki dönüşümünde dikkate alınması gereklidir. Tarımsal alanlar ve doğal/yarı doğal alanlar arasında meydana gelen dönüşümde, yaklaşık 2000 ha tarımsal alan doğal/yarı doğal alanlara dönüşmüştür. Her ne kadar tarımsal alanlarda büyük miktarda azalma olsa da sağlıklı bir ekosistem için tarımsal alanların doğal/yarı doğal alanlara dönüşmesi olumlu bir sonuçtur. Benzer olarak Çakır vd. (2019) yaptıkları çalışmada orman alanlarında artış, tarım alanlarında ise azalış meydana geldiğini belirtmektedirler. Orman alanlarında meydana gelen artışın, 1988 yılında kabul edilen 4342 sayılı Mera Kanunu'na istinaden, mera alanlarında gerçekleştirilen yeniden ağaçlandırma faaliyetleri olduğunu belirtmişlerdir. 
Tablo 4. AKAÖ sınıfları dönüşüm matrisi (2012-2018).

\begin{tabular}{|c|c|c|c|c|c|c|c|c|c|c|c|}
\hline \multirow{2}{*}{2012} & \multicolumn{11}{|c|}{2018} \\
\hline & S1 & $\mathbf{S 2}$ & S3 & S4 & S5 & S6 & S7 & S8 & S9 & S10 & S11 \\
\hline S1 & - & - & - & - & 0,01 & - & - & - & - & - & - \\
\hline S2 & - & - & 0,22 & 0,00 & 0,04 & 0,00 & - & 0,01 & 0,02 & - & - \\
\hline S3 & - & 0,59 & - & 2,85 & 0,18 & 0,00 & 0,00 & 0,72 & 0,23 & - & - \\
\hline S4 & - & - & 0,00 & - & 0,47 & 6,88 & 0,00 & 0,06 & 0,16 & - & - \\
\hline S5 & 0,01 & 0,07 & 0,29 & 0,21 & - & 0,06 & 0,01 & 1,53 & 0,88 & - & - \\
\hline S6 & 2,51 & 8,60 & 16,31 & 47,99 & 2,85 & - & 3,78 & 4,38 & 14,03 & - & - \\
\hline S7 & - & - & - & - & 0,00 & - & - & - & - & - & - \\
\hline S8 & - & 2,86 & 116,43 & 141,96 & 22,38 & 172,10 & 20,32 & - & $7.016,07$ & 9,58 & 14,50 \\
\hline S9 & - & 1,02 & 40,39 & 126,82 & 8,03 & 824,74 & 6,38 & $5.106,68$ & - & 11,98 & 7,19 \\
\hline S10 & - & - & 0,00 & - & - & - & - & 397,15 & 0,04 & - & - \\
\hline S11 & - & - & - & 0,00 & - & - & - & 27,89 & 111,83 & 31,30 & - \\
\hline
\end{tabular}

Not: 0,00 değerleri 0,005 ha'dan düşük dönüșümleri belirtmektedir. S1; Sürekli kentsel doku, S2; Süreksiz yoğun kentsel doku, S3; Süreksiz kentsel doku, S4; Endüstriyel/ticari alanlar, S5; Ulaşım altyapısı, S6; Maden /inşaat/kullanılmayan arazi, S7; Kentsel yeşil alanlar/spor tesisleri, S8; Tarımsal alanlar, S9;Doğal/yarı doğal alanlar, S10; Sulak alanlar, S11; Su yüzeyleri

AKAÖ sınıflarında meydana gelen değişim ve dönüşümlerin peyzaj yapısındaki parçalanma etkisinin belirlenmesi için yapılan metrik analizi ayrı bir tablo halinde Tablo 5'te verilmiştir. Tabloya göre incelenen peyzaj metrikleri açısından kentsel doku incelendiğinde sürekli kentsel doku, süreksiz yoğun kentsel doku ve süreksiz kentsel dokuda önemli bir değişim görülmemiştir. Buna karşın tarımsal alanlarda parça sayısı ve parça yoğunluğu azalmış, ortalama parça büyüklüğü artış göstermiştir. Bu bulgu 2012 yılına göre 2018 yılında tarımsal alanlardaki parçalanmanın azaldığını belirtmektedir. Aybek vd. (2021) parçalanmış tarım alanlarının, tarım aleti kullanımını sınırlandırdığını ve bu durumun gıda üretimini ekonomik olarak olumsuz etkilediğini belirtmektedir. Burdur Merkez İlçesi'ndeki tarımsal alanlarda parçalanmanın azalması daha ekonomik gıda üretimi açısından önem arz etmektedir. Doğal/yarı doğal alanlarda da parça sayısı ve parça yoğunluğu azalmış, ortalama parça büyüklüğü artmıştır. Bu değerler doğal/yarı doğal alanlarda da parçalanmanın azaldığını belirtmektedir. Tarımsal alanlarda ve doğal/yarı doğal alanlarda parçalanmanın azalmasına, AKAÖ sınıf dönüşüm matrisinde belirtilen iki sınıf arasında meydana gelen değişim ve dönüşümün neden olduğu düşünülmektedir. Ayrıca su yüzeyleri ve sulak alanlarda parça sayısının artış göstererek, ortalama parça büyüklügünün azalış göstermesi bu alanlarda parçalanmanın arttığını anlamına gelmektedir. Sulak alanların azalmasına paralel olarak parçalığının da artması ayrıca dikkate alınması gereken bir durum olarak karşımıza çıkmaktadır.

Tablo 5. AKAÖ sınıfları için sınıf metrikleri.

\begin{tabular}{|c|c|c|c|c|c|c|c|c|c|c|c|c|}
\hline \multirow{2}{*}{$\begin{array}{c}\text { Sinıf } \\
\text { Metrikleri }\end{array}$} & \multirow{2}{*}{ Yıl } & \multicolumn{11}{|c|}{ AKAÖ Sınıfları* } \\
\hline & & S1 & S2 & S3 & S4 & S5 & S6 & S7 & S8 & S9 & S10 & S11 \\
\hline \multirow{2}{*}{ NP } & 2012 & 166 & 693 & 1540 & 250 & 5 & 339 & 53 & 2039 & 1169 & 13 & 11 \\
\hline & 2018 & 165 & 697 & 1661 & 485 & 5 & 354 & 66 & 1285 & 481 & 14 & 13 \\
\hline \multirow{2}{*}{ PD } & 2012 & 0,11 & 0,44 & 0,98 & 0,16 & 0,00 & 0,22 & 0,03 & 1,30 & 0,75 & 0,01 & 0,01 \\
\hline & 2018 & 0,11 & 0,44 & 1,06 & 0,31 & 0,00 & 0,23 & 0,04 & 0,82 & 0,31 & 0,01 & 0,01 \\
\hline AREA_M & 2012 & 0,52 & 0,85 & 0,92 & 2,37 & 177,97 & 2,18 & 1,22 & 23,31 & 76,23 & 134,56 & $1.267,97$ \\
\hline $\mathbf{N}$ & 2018 & 0,54 & 0,86 & 0,96 & 1,86 & 184,17 & 4,64 & 1,45 & 35,44 & 187,36 & 100,35 & $1.061,41$ \\
\hline
\end{tabular}

*S1; Sürekli kentsel doku, S2; Süreksiz yoğun kentsel doku, S3; Süreksiz kentsel doku, S4; Endüstriyel/ticari alanlar, S5; Ulaşım altyapıs1, S6; Maden /inşaat/kullanılmayan arazi, S7; Kentsel yeşil alanlar/spor tesisleri, S8; Tarımsal alanlar, S9;Doğal/yarı doğal alanlar, S10; Sulak alanlar, S11; Su yüzeyleri

$\mathrm{Bu}$ araştırma, Burdur Merkez İlçesinin AKAÖ sınıfları hakkında çok önemli bulgular içerse de bazı kısıtlamalara maruz kalmıştır. Öncelikle, AKAÖ sınıfları arasındaki değişim ve dönüşümleri 6 yıl gibi kısa bir sürede izlemiştir. Bunun sebebi değişim ve dönüşümleri incelerken uydu görüntüsü üzerinden değil, raster veriye dönüştürülmüş vektör AKAÖ haritası üzerinden incelemesidir. İkinci olarak, Burdur İlinin tamamını değil sadece Merkez İlçesini incelemiş̧tir. Ayrıca bu araştırmada, peyzajdaki değişim sadece 5 sınıf metriği ile test edilmiştir. Burdur İlinin peyzaj yapısındaki değişimlerin tamamen anlaşılabilmesi için, gelecekteki araştırmalar daha uzun bir süre zarfında Burdur İlinin tamamını kapsayacak şekilde AKAÖ değişimlerini incelemelidir. 


\section{Sonuç ve Öneriler}

$\mathrm{Bu}$ araştırmada; Burdur merkez ilçesinin peyzajında yaşanan zamansal ve mekânsal değişimler peyzaj metrikleri kullanılarak (McGarigal ve Marks, 1995; McGarigal ve Cushman, 2002) analiz edilmiştir. Genel anlamda bulgular yorumlandığında ortaya çıkan en önemli sonuç; Burdur merkez ilçe kent peyzajı büyük ölçüde doğal ve yarı doğal alanlarını muhafaza eden, yoğun bir kentsel gelişmeye sahne olmamış ve hala önemli miktarda tarım alanına sahip olduğudur. Tüm bunlar doğal yapının ve tarım potansiyelinin korunarak sürdürülebilir ve örnek bir kent planlamasının ve gelişiminin sağlanması için çok önemli unsurlardır (Drummond ve Loveland, 2010; Syrbe ve Walz, 2012; Agaton vd., 2016; Zhang vd., 2016).

Bununla birlikte, en önemli sonuçlar arasında maden/inşaat/kullanılmayan arazi olarak kullanılan alanların büyük artış göstermesi ve sulak alanlardaki büyük azalmayı da belirtmek gerekir. Sulak alanlar bu süreçte tarımsal alan olarak kullanılmaya başlanmıştır. Doğal/yarı doğal alanlarda herhangi bir kaybın olmaması aksine parçalanmanın azalması çok olumlu bir sonuçtur. Sulak alanlardaki bu azalma başta biyo-çeşitlilik olmak üzere pek çok ekosistem servisinde azalma ve kayıplar anlamına gelmektedir. Sulak alanların farklı kullanımlara dönüştürülmesi parçalanmaya neden olarak, ekosistemi ve ekolojik süreçleri de tehlikeye sokmaktadır (Moser vd., 2002; Rocchini vd., 2006; Butt vd., 2015; Singh vd., 2016). Göller yöresi olarak adlandırılan bölgede yer alan Burdur Merkez İlçesinde, yüksek derecede su yüzeyleri ve sulak alan kaybının ciddi olumsuz sonuçları olacaktır. Bu azalmanın önüne geçilmesi gereklidir. Aslında sulak alanların koruma altında olması gereken alanlar olmasına rağmen bu azalmanın nasıl gerçekleştiği ayrı bir soru işaretidir. Kentsel doku da ise önemli bir parçalanma olmamak ile birlikte en büyük artış süreksiz kentsel dokuda meydana gelmiştir. Tarımsal alanların ve doğal/yarı doğal alanların bir kısmı süreksiz kentsel dokuya dahil edilmişstir.

Sonuç olarak, 6 yıl gibi kısa bir sürede meydana gelen peyzaj değişimleri önemli soru işaretlerini gündeme getirmektedir. Bu değişiklikler hiç şüphesiz ekosistem hizmetlerini ve ekolojik süreçleri olumsuz etkileyecektir. Ekosistem hizmetleri ve ekolojik süreçlerin aksamaması için gerekli önlemler alınmalıdır.

Bu bağlamda Burdur kent geneli için yapılması gereken en önemli eylemler şunlardır;

A. Öncelikle Burdur kenti ve çevresine yönelik olarak peyzajı niceliksel yönden analiz eden bu mevcut araştırma benzeri çalışmaların arttırılması, geçmişten günümüze ve geleceğe yönelik strateji ve politikalar ile fiziksel planlama kararlarının daha sistematik bir temele oturmasına yardımcı olacaktır.

B. Kentteki bütün paydaşların katımlıyla bir kentsel geniş kapsamlı yeşil alt yapı stratejisi ve planı hazırlanmasıdır. Bu konuda Mehmet Akif Ersoy Üniversitesinin varlığı önemli bir kazanım ve süreci kolaylaştırıcı bir unsurdur çünkü üniversitesinin başta peyzaj mimarlığı bölümü olmak üzere birimleri bu konuda önemli bir rol oynayabilir.

C. Yeşil alt yapı stratejisine bir hazırlık olarak kent genelinin yeşil ve mavi altyapı bileşenlerinin envanterinin ve haritalanmasının yapılması gerekir. Bu güncel veri ve haritalar çok önemli bir altlık oluşturacaktır.

D. Yeşil ve mavi alt yapı bileşenleri ortaya konulur ve haritalanırken, Burdur'un temel peyzaj bileşenlerinden olan su yüzeyleri (akarsu ve göller) ve sulak alanlara ayrıca önem verilmelidir. Ayrıca bu bileşenler peyzajda bağlantı sağlayan elemanlar olarak parçalanma sorununa önemli bir önlem olacaktır.

E. Kentteki yeşil alan planlama ve tasarımlarında, Burdur'u iklim değişikliği etkilerine karşı daha dirençli hale getirecek ve mevcut ekosistem servislerini en üst düzeye çıkaracak yaklaşımlar benimsenmelidir.

F. İleriye yönelik alınacak kentsel gelişim kararlarında, kentsel dokuda yoğun apartman bloklarından ziyade, kentsel yeşil altyapıya destek verecek bahçeli konutlar veya aralarında geniş açık-yeşil alanların yer aldığ 1 yapı bloklarının olduğu yapılaşma biçimi teşvik edilmelidir.

\section{Kaynaklar}

1. Agaton, M., Setiawan, Y., Effendi, H. (2016). Land use/land cover change detection in an urban watershed: A case study of upper Citarum Watershed, West Java Province, Indonesia. Procedia Environmental Sciences, 33, 654-660. doi: 10.1016/j.proenv.2016.03.120

2. Alkan, M., Oruc, M., Yildirim, Y., Seker, D.Z., Jacobsen, K. (2013). Monitoring spatial and temporal land use/cover changes; A case study in Western Black Sea Region of Turkey. Journal of the Indian Society of Remote Sensing, 41, 587-596. doi:10.1007/s12524-012-0227-2 
3. Alphan, H. (2003). Land-use change and urbanization of Adana, Turkey. Land Degradation \& Development, 14, 575-586. doi:10.1002/ldr.581

4. Ataol, M. (2010). Burdur Gölü'nde seviye değişimleri. Coğrafi Bilimler Dergisi, 8(1), 77-92. doi: 10.1501/Cogbil_0000000105

5. Aybek, A., Kuzu, H., Karadöl, H. (2021). Türkiye'nin ve tarım bölgelerinin tarımsal mekanizasyon düzeyindeki değişimlerin son on yıl (2010-2019) ve gelecek y1llar (2020-2030) için değerlendirilmesi. Kahramanmaraş Sütçü Imam Üniversitesi Tarım ve Doğa Dergisi, 24(2), 319-336. doi:10.18016/ksutarimdoga.vi.747163

6. Bateman, I.J., Harwood, A.R., Mace, G.M., Watson, R.T., Abson, D.J., Andrews, B., Binner, A., Crowe, A., Day, B.H., Dugdale, S., Fezzi, C., Foden, J., Hadley, D., Haines-Young, R., Hulme, M., Kontoleon, A., Lovett, A.A., Munday, P., Pascual, U., Paterson, J., Perino, G., Sen, A., Siriwardena, G., van Soest, D., Termansen, M. (2013). Bringing ecosystem services into economic decision-making: Land use in the United Kingdom. Science, 341(6141), 45. doi: 10.1126/science. 1234379

7. Bayar, R., Karabacak, K. (2017). Ankara ili arazi örtüsü değişimi (2000-2012). Coğrafi Bilimler Dergisi, 15(1), 59-76.

8. Bolliger, J., Kienast, F. (2010). Landscape functions in a changing environment. Landscape Online, 21, 1-5. doi: 10.3097/lo.201021

9. Butt, A., Shabbir, R., Ahmad, S.S., Aziz, N. (2015). Land use change mapping and analysis using Remote Sensing and GIS: A case study of Simly Watershed, Islamabad, Pakistan. The Egyptian Journal of Remote Sensing and Space Science, 18, 251-259. doi: 10.1016/j.ejrs.2015.07.003

10. Costanza, R., d'Arge, R., de Groot, R., Farberparallel, S., Grasso, M., Hannon, B., Limburg, K., Naeem, S., O'Neill, R.V., Paruelo, J., Raskin, R.G., Sutton, P., van den Belt, M. (1997). The value of the world's ecosystem services and natural capital. Nature, 387, 253-260. doi: 10.1038/387253a0

11. Çakır, G., Kaya, L.G., Yücedağ, C., Bayram, S. (2019). Determination of the effects of alucra forest planning unit's population dynamics on land use changes. Kastamonu University Journal of Forestry Faculty, 19(1), 35-46. doi: 10.17475/kastorman.543415

12. Dengiz, O., Demiră̆ Turan, İ. (2014). Uzaktan algılama ve coğrafi bilgi sistem teknikleri kullanılarak arazi örtüsü / arazi kullanımı zamansal değişimin belirlenmesi: Samsun Merkez İlçesi örneği (19842011). Türkiye Tarımsal Araştırmalar Dergisi, 1(1), 78-90. doi:10.19159/tutad.45474

13. Drummond, M.A., Loveland, T.R. (2010). Land-use pressure and a transition to forest-cover loss in the Eastern United States. BioScience, 60, 286-298. doi: 10.1525/bio.2010.60.4.7

14. EEA (2020a). Urban atlas, copernicus land monitoring service - part of the copernicus programme, European Environment Agency, https://land.copernicus.eu/local/urban-atlas (15.11.2020).

15. EEA (2020b). Mapping guide v6.1 for a european urban atlas, copernicus land monitoring service - part of the copernicus programme, European Environment Agency, https://land.copernicus.eu/usercorner/technical-library/urban_atlas_2012_2018_mapping_guide_v6-1.pdf (15.11.2020).

16. ESRI 2020. ArcGIS 10.8 Software, Environmental Systems Research Institute, Redlands, CA.

17. Gül, M., Zorlu, K., Gül, M. (2019). Assessment of mining impacts on environment in Muğla-Aydın (SW Turkey) using landsat and google earth imagery. Environmental Monitoring and Assessment, 191, 655. doi:10.1007/s10661-019-7807-3

18. Haberl, H., Erb, K.-H., Krausmann, F., Loibl, W., Schulz, N., Weisz, H. (2001). Changes in ecosystem processes induced by land use: Human appropriation of aboveground NPP and its influence on standing crop in Austria. Global Biogeochemical Cycles, 15, 929-942. doi: 10.1029/2000gb001280

19. Hao, R., Yu, D., Liu, Y., Liu, Y., Qiao, J., Wang, X., Du, J. (2017). Impacts of changes in climate and landscape pattern on ecosystem services. Science of The Total Environment, 579, 718-728. doi: 10.1016/j.scitotenv.2016.11.036

20. Hepcan, Ş. (2013). Analyzing the pattern and connectivity of urban green spaces: A case study of Izmir, Turkey. Urban Ecosystems, 16, 279-293. doi:10.1007/s11252-012-0271-2

21. Hepcan, Ş., Coşkun Hepcan, Ç., Kılıçaslan, Ç., Özkan, M.B., Koçan, N. (2013). Analyzing landscape change and urban sprawl of a Mediterranean coastal landscape: A case study of Izmir, Turkey. Journal of Coastal Research, 29(2), 301-310. doi: 10.2112/JCOASTRES-D-11-00064.1

22. Kara, B. (2019). Agrarian and wetland areas under metropolitan threats: Learning from the case of Inciralt1, Izmir (Turkey). Applied Ecology and Environmental Research, 17(6), 15087-15102. doi: 10.15666/aeer/1706_1508715102

23. Kara, B., Esbah, H., Deniz, B. (2013). Monitoring and analyzing land use/land cover changes in a developing coastal town: A case study of Kusadasi, Turkey. Journal of Coastal Research, 29(6), 13611372. doi: 10.2112/JCOASTRES-D-11-00140.1 
24. Karaali, İ., Ersoy Tonyaloğlu, E., Kesgin Atak, B., Nurlu, E. (2020). Alan kullanımı/arazi örtüsü değişiminin mekansal ve zamansal analizi: İzmir/Türkiye Örneği. Uluslararası Doğu Anadolu Fen Mühendislik ve Tasarım Dergisi, 2, 308-324. doi:10.47898/ijeased.800037

25. Kaya, L.G., Yücedağ, C., Duruşkan, Ö. (2015). Burdur gölü havzasının çevresel açıdan irdelenmesi. Mehmet Akif Ersoy Üniversitesi Fen Bilimleri Enstitüsü Dergisi, 6(1), 6-10.

26. Khan, M.M.H., Bryceson, I., Kolivras, K.N., Faruque, F., Rahman, M.M., Haque, U. (2015). Natural disasters and land-use/land-cover change in the southwest coastal areas of Bangladesh. Regional Environmental Change, 15, 241-250. doi: 10.1007/s10113-014-0642-8

27. Kumar, N., Singh, S.K., Singh, V.G., Dzwairo, B. (2018). Investigation of impacts of land use/land cover change on water availability of Tons River Basin, Madhya Pradesh, India. Modeling Earth Systems and Environment, 4, 295-310. doi:10.1007/s40808-018-0425-1

28. Kumar, N., Singh, S.K., Srivastava, P.K., Narsimlu, B. (2017). SWAT Model calibration and uncertainty analysis for streamflow prediction of the Tons River Basin, India, using Sequential Uncertainty Fitting (SUFI-2) algorithm. Modeling Earth Systems and Environment, 3, 30. doi: 10.1007/s40808-017-0306-Z

29. Lawler, J.J., Lewis, D.J., Nelson, E., Plantinga, A.J., Polasky, S., Withey, J.C., Helmers, D.P., Martinuzzi, S., Pennington, D., Radeloff, V.C. (2014). Projected land-use change impacts on ecosystem services in the United States. Proceedings of the National Academy of Sciences, 111, 74927497. doi: 10.1073/pnas.1405557111

30. Lorencová, E., Frélichová, J., Nelson, E., Vačkář, D. (2013). Past and future impacts of land use and climate change on agricultural ecosystem services in the Czech Republic. Land Use Policy, 33, 183-194. doi: 10.1016/j.landusepol.2012.12.012

31. McGarigal, K., Cushman, S.A. (2002). Comparative evaluation of experimental approaches to the study of habitat fragmentation effects. Ecological Applications, 12, 335-345. doi: 10.2307/3060945

32. McGarigal, K., Cushman, S.A., Ene, E. (2012). FRAGSTATS v4: spatial pattern analysis program for categorical and continuous maps. Computer software program produced by the authors at the University of Massachusetts, Amherst. http://www.umass.edu/landeco/research/fragstats/fragstats.html (15.11.2020).

33. McGarigal, K., Marks, B.J. (1995). FRAGSTATS: spatial pattern analysis program for quantifying landscape structure. Gen. Tech. Rep. PNW-GTR-351. Portland, OR: U.S. Department of Agriculture, Forest Service, Pacific Northwest Research Station. 122 p. doi: 10.2737/PNW-GTR-351

34. Mitchell, M., Bennett, E., Gonzalez, A. (2015). Strong and nonlinear effects of fragmentation on ecosystem service provision at multiple scales. Environmental Research Letters, 10, 094014. doi: 10.1088/1748-9326/10/9/094014

35. Mooney, H.A., Duraiappah, A., Larigauderie, A. (2013). Evolution of natural and social science interactions in global change research programs. Proceedings of the National Academy of Sciences, 110, 3665-3672. doi: 10.1073/pnas.1107484110

36. Moser, D., Zechmeister, H.G., Plutzar, C., Sauberer, N., Wrbka, T., Grabherr, G. (2002). Landscape patch shape complexity as an effective measure for plant species richness in rural landscapes. Landscape Ecology, 17, 657-669. doi: 10.1023/a:1021513729205

37. Oğuz, H., Zengin, M. (2011). Peyzaj patern metrikleri ve landsat 5 tm uydu görüntüleri kullanılarak arazi örtüsü/arazi kullanımı değişimi analizi (1984-2010): Kahramanmaraş örneği, I. Ulusal Akdeniz Orman ve Çevre Sempozyumu, 26-28 Ekim 2011, Kahramanmaraş.

38. Paudel, D., Thakur, J.K., Singh, S.K., Srivastava, P.K. (2014). Soil characterization based on land cover heterogeneity over a tropical landscape: An integrated approach using earth observation data-sets. Geocarto International, 30(2), 218-241. doi: 10.1080/10106049.2014.905639

39. Petropoulos, G.P., Kalivas, D.P., Georgopoulou, I.A., Srivastava, P.K. (2015). Urban vegetation cover extraction from hyperspectral imagery and geographic information system spatial analysis techniques: Case of Athens, Greece. Journal of Applied Remote Sensing, 9, 096088. doi: 10.1117/1.jrs.9.096088

40. Renó, V., Novo, E., Escada, M. (2016). Forest fragmentation in the lower Amazon Floodplain: Implications for biodiversity and ecosystem service provision to riverine populations. Remote Sensing, 8, 886. doi: 10.3390/rs8110886

41. Rocchini, D., Perry, G.L.W., Salerno, M., Maccherini, S., Chiarucci, A. (2006). Landscape change and the dynamics of open formations in a natural reserve. Landscape and Urban Planning, 77, 167-177. doi: 10.1016/j.landurbplan.2005.02.008

42. Roth, D., Moreno-Sanchez, R., Torres-Rojo, J.M., Moreno-Sanchez, F. (2016). Estimation of human induced disturbance of the environment associated with 2002, 2008 and 2013 land use/cover patterns in Mexico. Applied Geography, 66, 22-34. doi: 10.1016/j.apgeog.2015.11.009 
43. Singh, S.K., Srivastava, P.K., Singh, D., Han, D., Gautam, S.K., Pandey, A.C. (2015). Modeling groundwater quality over a humid subtropical region using numerical indices, earth observation datasets, and X-ray diffraction technique: A case study of Allahabad District, India. Environmental Geochemistry and Health, 37, 157-180. doi: 10.1007/s10653-014-9638-Z

44. Singh, S.K., Srivastava, P.K., Szabó, S., Petropoulos, G.P., Gupta, M., Islam, T. (2016). Landscape transform and spatial metrics for mapping spatiotemporal land cover dynamics using earth observation data-sets. Geocarto International, 32(2), 113-127. doi:10.1080/10106049.2015.1130084

45. Syrbe, R., Walz, U. (2012). Spatial indicators for the assessment of ecosystem services: Providing, benefiting and connecting areas and landscape metrics. Ecological Indicators, 21, 80-88. doi: 10.1016/j.ecolind.2012.02.013

46. Tanner, E.P., Fuhlendorf, S.D. (2018). Impact of an agri-environmental scheme on landscape patterns. Ecological Indicators, 85: 956-965. doi: 10.1016/j.ecolind.2017.11.043

47. Turgut, Y.Ş., Keleş, B., Şenol, S. (2021). Toprak veritabanı kullanılarak Ceyhan Ovası arazi kullanımında zamansal değişimlerin belirlenmesi. Kahramanmaraş Sütçü İmam Üniversitesi Tarım ve Doğa Dergisi, 24(3), 622-631. doi:10.18016/ksutarimdoga.vi.737302

48. TüİK 2021. Adrese dayalı nüfus kayı sistemi, Türkiye İstatistik Kurumu, https://biruni.tuik.gov.tr/medas/?kn=95\&locale=tr (10.04.2021).

49. Uzun, O., Müderrisoğlu, H., Demir, Z., Kaya, L.G., Gültekin, P., Gündüz, S. (2015). Yeşilırmak havzası peyzaj atlası. T.C. Orman ve Su İşleri Bakanlığı, Doğa Koruma ve Milli Parklar Genel Müdürlüğü adına AKS Planlama ve Mühendislik Limited Şirketi, Ankara, 259 s.

50. Yigitbaşıı̆̆lu, H., Uğur, A. (2010). Burdur Gölü Havzasında arazi kullanım özelliklerinden kaynaklanan çevre sorunları. Ankara Üniversitesi Çevrebilimleri Dergisi, 2(2), 129-143. doi: 10.1501/Csaum_0000000032

51. Zadbagher, E., Becek, K., Berberoglu, S. (2018). Modeling land use/land cover change using remote sensing and geographic information systems: Case study of the Seyhan Basin, Turkey. Environmental Monitoring and Assessment, 190, 494. doi:10.1007/s10661-018-6877-y

52. Zhang, J., Fu, M., Tao, J., Huang, Y., Hassani, F.P., Bai, Z. (2010). Response of ecological storage and conservation to land use transformation: A case study of a mining town in China. Ecological Modelling, 221(10), 1427-1439. doi: 10.1016/j.ecolmodel.2010.02.011

53. Zhang, L., Nan, Z., Xu, Y., Li, S. (2016). Hydrological impacts of land use change and climate variability in the headwater region of the Heihe River Basin, Northwest China. PLOS ONE, 11, e0158394. doi: 10.1371/journal.pone.0158394 